\title{
Víctor Pérez-Díaz*
}

\section{EL SUEÑO DE LA RAZÓN PRODUCE MONSTRUOS. A PROPÓSITO DEL TEMA DE LAS DEMANDAS Y CAPACIDADES CÍVICAS DE HOY}

En el artículo se exploran algunos factores culturales de las dificultades de las sociedades occidentales para hacer frente a la crisis actual, entendida como una crisis global (económica, social, política y cultural) profunda. Crisis que da un mentís a las teorías del final de la historia, y apunta a un drama abierto a varias posibilidades, que incluyen una aproximación a una «sociedad buena», variantes de un modus vivendi entre diversos segmentos de la sociedad, y experiencias destructivas, y autodestructivas, importantes.

Palabras clave: crisis social, cambios estructurales, cambio global, prospectiva.

Clasificación JEL: A13, M14, O32.

\section{Introducción}

A lo largo del artículo sugiero que una de las claves de la dificultad presente estriba en la difusión de un marco interpretativo que centra la atención en el sector (dirigente) de la sociedad que protagoniza el debate en el espacio público. Éste se articula en torno a un contraste entre elites y contra-elites, establishment y anti-establishment, con sus entornos económicos, sociales y culturales (mediáticos y otros) correspondientes ${ }^{1}$. Unos y otros comparten una cultura agónica de la política, lo que tiene un efecto profundo de ofuscación y distorsión del debate público, y reduce sustancialmente la capacidad estratégica de la sociedad en su

\footnotetext{
* Presidente del Centro de Investigación Analistas Socio-Políticos, ASP, Madrid
}

conjunto para resolver los problemas de la crisis, incluido, en primer término, el problema de la recreación continua de la propia comunidad política.

Apunto asimismo a la posibilidad de desarrollar un marco interpretativo diferente, centrado en el proyecto de un espacio público como el lugar de una conversación (deliberación, experimentación) en la que se compromete una sociedad suficientemente razonable y básicamente reconciliada, cuyo agente principal puede ser una masa crítica de la propia ciudadanía, de los ciudadanos de a pie o, si se quiere, de la sociedad civil; pero de una que opera en un contexto relacional y reflexivo.

\footnotetext{
1 Por mor de simplificar el argumento, dejo deliberadamente a un lado una discusión complementaria relativa a la mutación, y degeneración, del establishment (y el anti-establishment) en la dirección de un régimen oligárquico (o dominado por lo que he llamado «triarquías oligárquicas» PÉREZ-DÍAZ, 2008, 85-104)
} 
Aludo finalmente (aunque aplazo el desarrollo del tema para otro momento) a que ello depende, a su vez, del desarrollo del núcleo de la tradición de sentido común y de sentido moral ${ }^{2}$ que, en diversas modalidades y con distintos lenguajes culturales, pueda existir, en un grado u otro, en la sociedad en cuestión.

\section{El sueño de la razón, y la razón despierta}

Un cuarto de siglo después del colapso del totalitarismo soviético y de que algunos anunciaran el fin de la historia y un nuevo orden mundial, en el sancta sanctorum de ese orden, Occidente, se ha producido una crisis profunda de dos de sus instituciones clave, la democracia y el capitalismo ${ }^{3}$. Como si, en lugar de asistir al fin de la historia lo hiciéramos a una nueva fase, una más, de un proceso interminable que alternara y mezclara luces y sombras.

La crisis política y económica supone una fractura social. En España se combina con un grave riesgo de fractura territorial; en Europa, con un entramado institucional sin encajar; en Estados Unidos, con una sensación de pérdida de rumbo. Le acompaña un alto grado de desconcierto, propio de quienes no saben cómo manejar, o siquiera discutir, porque no entienden, aquella combinación de crisis.

Sucede que a las dificultades objetivas se unen los inconvenientes de una deliberación sometida a un ritmo apresurado, y a un marco interpretativo que favorece una opción desenfocada. A la hora de resolver la crisis, se nos insta a los ciudadanos a hacerlo de inmediato, buscando la gran decisión, el acto de voluntad suprema por el que otorgar nuestra confianza

\footnotetext{
2 Me refiero a una tradición de common sense en el sentido utilizado por VOEGELIN (1989, 28-29), y de moral sense en la referencia de MACINTYRE $(2006,193)$. Asimismo (y en parte en relación con lo anterior), dejo para otro momento analizar el contraste entre la situación de Occidente y la del resto del mundo.

3 No la mera idea de la democracia, sino la experiencia de la democracia (MARSH, 2014). Tampoco cualquier variedad de capitalismo, como sugiere la literatura sobre este tema (HALL, 2016), matizando posiciones como la de STREECK (2014)
}

a unos salvadores u otros. Salvadores o exorcistas, según se mire.

Con frecuencia se nos da a elegir entre dos héroes, o antihéroes, asimétricos, muy distintos pero con rasgos compartidos curiosos. Por un lado, tenemos un establishment bastante responsable de la crisis actual (contando con la anuencia y el descuido de muchos). Unas veces, nos aconseja paciencia, alardea de su tacticismo y apela al orden natural de las cosas. Otras, nos distrae con la inestimable ayuda de la industria de la cultura y el entretenimiento, y en parte la educación, con el culto del futuro y un horizonte abierto, como ellos dicen, a la conquista de Marte y diversas galaxias. Por otro lado, tenemos variedades de un anti-establishment que nos ofrece el porvenir, surrealista, de un retorno al pasado de alguna variante de bonapartismo, totalitarismo, $u$ otras pesadillas de los dos últimos siglos. Cada uno a su manera son políticamente correctísimos y, como tales, un tanto autistas y un mucho ansiosos, nos aturden y nos predisponen a la confusión. Nos adormecen de varios modos. Los unos propician un estado de sonambulismo, los otros nos alientan a soñar que volamos y asaltamos los cielos mientras caemos por el precipicio.

Para la ciudadanía de a pie, el resultado de combinar tanto estrés acumulado (en tan poco tiempo) con semejante disyuntiva es un alto riesgo de ofuscación mental, incluso para discernir lo que pudiera haber de razonable en los dos extremos. Porque la razón requiere alguna forma de conversación amistosa, lejos del ruido compulsivo de las descalificaciones mutuas; y una dosis de tiempo y calma. Calma porque, si, por poner ejemplos que tenemos cerca, no hemos resuelto los problemas del mercado de trabajo, de la educación o de Cataluña en 30 o 40 años, llevados de la mano por tantas elites dilectísimas y con tantos arrebatos de indignación por el camino, no es cosa de pensar que lo haremos ahora en un repente y mediante un acto de voluntad suprema.

La verdad es que puestos a elegir entre unos y otros, y mejor aún, a elegir entre ni unos ni otros, convendría 
ser razonable; y evitar, justamente, la situación que evoca el capricho de Goya «El sueño de la razón produce monstruos»: la de un hombre dormitando, la cabeza hundida, las piernas entrecruzadas e inmóvil, rodeado de figuras siniestras surgiendo de su mente, y a las que su razón, perdida, diera alas.

Aquel capricho lo dibujó Goya en 1797, y al año siguiente nos dio un retrato de Gaspar Melchor de Jovellanos que parece su antítesis. El personaje del capricho y Jovellanos tienen una hechura y una disposición corporal bastante semejantes. Pero Jovellanos está pintado contra un fondo de una luminosidad entre plateada y dorada, y sus ojos bien abiertos parecen considerar, precavidos, una situación compleja, una tarea por hacer. La razón ausente del capricho habría dado paso a una razón alerta.

Alerta... lo que dure. Que Jovellanos encontrara la manera de evitar la sinrazón de unos y de otros mucho tiempo, es dudoso. Sus últimas palabras, «ipaís sin cabeza, desgraciado de mí!», sugieren un profundo desengaño. Aunque también pueden interpretarse como una advertencia a quienes, a través del tiempo, queramos escucharle. Porque lo interesante de la historia, como de la vida, es que no suelen obedecer a leyes que marquen un destino. Son dramas abiertos. Que los sueños de la razón produzcan monstruos, y éstos nos aniquilen es solo una posibilidad. También podemos despertar del sueño, interpretarlo, aprender algo. Y ya se verá lo que el aprendizaje dura. Siempre se podrá olvidar, y volverlo a aprender.

Con este ánimo esperanzado, que no iluso, repensemos un momento la situación actual. Cabe razonar. Cabe razonar juntos. Cabe incluso que no tengamos otra forma de razonar sobre los bienes comunes que la de hacerlo juntos.

En tal caso, es preciso escucharse, deliberar, decidir, pero hacerlo como se hace en un experimento, atendiendo a sus consecuencias, sopesadas por unos y por otros, rectificar, aprender y seguir aprendiendo, darse cuenta de lo olvidado por el camino (probablemente porque los otros nos llaman la atención sobre ello), volverlo a recordar. Todo ello en un clima con un grado suficiente de conversación razonable y de amistad cívica ${ }^{4}$.

Claro es que, siendo realistas, habida cuenta el odio y la confusión mental ya acumulados, no deberíamos esperar un grado demasiado alto de conversación razonable y de amistad cívica en las sociedades occidentales de hoy. Pero, y sin descontar nunca los milagros (porque, ¿quiénes somos nosotros para excluirlos?), al menos, si el progreso que soñamos parece inalcanzable, debemos intentar, y esperar, que no sea totalmente imposible ${ }^{5}$.

\section{Un elogio de la música celestial}

Pues bien, con este talante al tiempo realista y optimista, podemos oponer a la cultura dominante del establishment y del anti-establishment, que es la cultura de la voluntad de poder, una cultura alternativa que sería la de la convivencia razonable. E intentar nuestra suerte.

Para empezar, no hay razón para que los ruidos belicistas, si no cainitas, algunos dirían que incluso satánicos, no deban y puedan reducirse sustancialmente. Conviene aplicar reglas de civilidad en la conversación y facilitar la heterogeneidad de los grupos implicados en el debate colectivo para evitar la tendencia hacia la escalada a los extremos ${ }^{6}$. Sobre todo, conviene cuidar el lenguaje y la retórica. Parece obvio que, en las

\footnotetext{
4 Digamos que, incluso, aplicando el principio de la caridad de DAVIDSON (2001), tratando de realizar una interpretación racional y coherente de lo que nos dicen los demás, en lo posible, o, si se quiere, tratando de entender lo que nos dicen atendiendo a lo que nos quieren decir.

5 Como decía un amigo mío perteneciente a la tribu de los aronianos, de los discípulos de Raymond Aron, que acabó enseñando, por azares del destino y para evitar los furores de algunos totalitarios de su época, en Nueva Inglaterra. Me refiero a Stanley Hoffmann, recordado en HALL (en prensa).

6 Veáse SCHUDSON (1997) sobre las limitaciones habituales de la conversación cívica; SUNSTEIN (2008) sobre la importancia de la heterogeneidad del público a estos efectos; OLSEN (2013) sobre la influencia de las instituciones de accountability; también THOMPSON (2016) sobre el carácter del lenguaje político. Y a tener en cuenta, en otro nivel de análisis, a GIRARD (2007).
} 
actuales circunstancias, los dramas políticos suelen estar sobreactuados. La crisis actual tiende a ser manejada (no siempre, no en todas partes) partiendo del supuesto de que la sociedad está enfrentada en campos enemigos, o, como suele decirse, intensamente polarizada. Cada vez más, dicen. Pero no es así.

En rigor, lo que esa polarización tan acusada refleja es, ante todo, la experiencia de un determinado sector de la sociedad, quizá el formado por el establishment y el anti-establishment, y en particular por el medio social de muchos (nunca todos) políticos profesionales y agentes mediáticos, y entornos difusos de intelectuales y agentes culturales y expertos. Una parte interesante, sí, de la sociedad, empeñada en asaltar el Olimpo y edificar su torre de Babel, y que siente su vida como la expresión de una voluntad de poder.

Pero esto no se aplica a toda la sociedad, cuya mayor parte está probablemente un poco más interesada en vivir y en convivir. Quizá esta sociedad, la ciudadanía de a pie, la sociedad civil, si se quiere, vive otro tipo de vida y se mueve en otra longitud de onda. Es como la multitud amable de la Pradera de San Isidro pintada por Goya, diez años antes que el capricho del sueño de la razón, al borde del modesto Manzanares, San Francisco el Grande al fondo, relajada entre risas y escarceos, entretenida en compartir conversación y merienda, con sus gentes de alcurnia, y sus gentes de a pie, que casi parecen gozosas de estar juntas, aunque su gozo pueda acabar por revelarse equívoco (Hagen y Rainer, 2016). En todo caso, a la sociedad de a pie, en general, la llamada polarización política le afecta, sí, pero le afecta, de entrada, menos; aunque no se excluye que no se deje contagiar por el belicismo y el cainismo de las elites y contra-elites de turno, a su debido tiempo. Como tal vez les acabara ocurriendo a algunas de aquellas mismas figuras goyescas.

La sociedad norteamericana, por ejemplo, cuyos partidos sí se han polarizado ideológicamente desde los años setenta del siglo pasado, no lo ha hecho tanto ella misma. Los debates y las campañas presidenciales del momento pueden ser virulentos y dejar un reguero de agravios. Pero, a lo largo de las dos últimas décadas, la consistencia ideológica ha caracterizado y caracteriza a un porcentaje de norteamericanos que se sitúa entre el 10 y el 21 por 100; y, lógicamente, cabe suponer que la inmensa mayoría restante de los americanos sin opiniones tan coherentes en clave conservadora o liberal (o progresista) puede preferir que sus partidos se encuentren a medio camino y acepten compromisos entre sí (Nye, 2015, 87). Lo que, por poner otro ejemplo, más próximo, recuerda las opiniones recientes de los españoles (de todas las partes de España) sobre el exceso de polarización y confrontación ideológica que los partidos políticos introducen en el debate sobre las cuestiones territoriales e identitarias (Pérez-Díaz, Mezo y Rodríguez, 2012, 192 y ss.).

Hay como un hiato entre dos culturas vividas, la de la gente de a pie, al menos cuando aplica su buen sentido, y la gente de alcurnia, la que iría en carroza, por así decirlo, cuando se deja llevar de su posible mezcla de ilustración y de soberbia.

Encontrar el modo de manejar el contraste entre estas dos experiencias de vida y estos dos universos de discurso no es tarea fácil. Desde hace mucho tiempo impera el universo cultural que define el conflicto político como un conflicto de intereses poco menos que irreconciliables, y de ideas fijas reconvertidas en ideologías o rebautizadas como tales, que se entrecruzan en una batalla reminiscente de la de los ejércitos en la noche, del poema de Arnold (1995, 92). Lo que se dirime en esa batalla es quién impondrá su voluntad al otro. Frente a tanto delirio voluntarista, introducir el contrapunto del universo cultural que prima la conversación razonable y la amistad cívica parece poco menos que imposible. Suena a «música celestial» 7 .

¿Qué se puede hacer? Podemos sumarnos a la confusión, o ponernos muy tristes. Pero si optamos por hacer algo distinto, lo primero es reivindicar el interés,

\footnotetext{
7 y como tal, puede suscitar la ironía, o la censura de muchos, incluidos tantos esprits forts que usan sus energías en que todo cambie, quizá para que solo cambie lo que cambia solo.
} 
la relevancia de la música celestial. Sí, ya sé que estamos inmersos en una cultura política que enfatiza la tradición de los «animales políticos», de Maquiavelo, de Nietzsche e tutti quanti. Pero, en fin, junto a Dionisos también estaba Apolo; e incluso Pitágoras y Platón y la ciudad de Dios, y la idea de armonía y del orden del cielo aplicado a la tierra. La política antigua. Y también las corrientes mal llamadas utópicas de los últimos ¿dos, cinco, doce siglos? ${ }^{8} ¿$ Está todo esto tan anticuado? Pero, ¿qué culpa tenemos de que nuestros líderes, políticos, agentes mediáticos y expertos, incluidos no pocos científicos sociales, tengan, tengamos, una formación histórica tan ligera?

Por lo pronto, esta apuesta por la música celestial podría descolocar un poco al mundo de la cultura del entretenimiento, y fomentar en él cierta confusión, sugiriéndole que quizá pudiera convenirle ponerse a la última moda retornando a la historia antigua, adoptando el lenguaje, tal vez el vestido y los gestos, del antiguo Egipto o de los tiempos de alguna remota dinastía china. Quizá las redes sociales acogerían el experimento, las nuevas sensibilidades del momento fugaz responderían al estímulo, y todo ello acabaría siendo (al menos por un tiempo) muy, muy in.

Así se podría ganar un tiempo precioso, y reducir la tensión emocional del ambiente, con el objetivo de desarrollar un argumento ad hominem con el que atacar el flanco débil de un adversario que pretende dirigir el curso de la historia careciendo de la capacidad de hacerlo.

Pero aquí hay que introducir un matiz. No hay que imitar a las elites y las contra-elites siendo tan belicistas como ellas. Hay que tener en cuenta que se trata de llevar adelante una gran estrategia pacífica, que apunta a una sociedad diversa y un tanto contenciosa, pero profundamente reconciliada. No hay por qué herir en exceso la sensibilidad de las elites (y,

\footnotetext{
8 Sin excluir experiencias de áreas culturales distintas de la occidental, y dentro de esta última, atendiendo no solo a experiencias modernas y clásicas sino, asimismo, a la llamada «democracia medieval» (DALARUN, 2012).
}

se sobreentiende, de las contra-elites, que no son sino sus rivales miméticos). Una herida extrema no es aconsejable, porque hay que hacerse a la idea de que, como los pobres del Evangelio, también las elites estarán siempre con nosotros, y siempre nos harán falta, en alguna medida, dentro de los límites de la razón; es decir, en el entendimiento de que el protagonismo no es suyo, y la justicia es de todos.

Como se ha llegado a decir: «no podemos vivir con los políticos y tampoco podemos vivir sin ellos» (Fawcett, 2014). Hay que comprenderles, hay que corregirlos, hay que ayudarles a que rectifiquen, hay que echarles de sus puestos cuando sea menester. Con prontitud pero sin acritud. Con gratitud incluso; porque han de manejarse con problemas complejos que atañen a los bienes comunes, y de los que muchos ciudadanos comunes simplemente se desentienden.

\section{El problema de la capacidad estratégica de los agentes en un contexto relacional y reflexivo}

El argumento ad hominem dirigido a las elites y contra-elites de hoy consiste en basarnos en sus propios actos para cuestionar su discurso; es decir, cuestionar sistemáticamente, pero también, insisto, de manera graduada, su capacidad estratégica para resolver los problemas de la sociedad. Es una capacidad estratégica de la que, en muy buena medida, carecen, como demuestra, justamente, una y otra vez, la falta de solución de los problemas.

Ello no obsta, sin embargo, para que elites y contraelites no "sepan sus cosas», y que lo que sepan no tenga un núcleo razonable; ni significa que carezcan de sensibilidad alguna por el cuidado del bien común. Obviamente la tienen. Se trata tan solo de recordar los límites normales de esa capacidad; lo que les aconsejaría ser humildes, y tratar a la ciudadanía en pie de igualdad. Y es lógico que tengan esos límites, a pesar de toda la grandilocuencia que suele acompañar el simbolismo político moderno. Grandilocuencia en 
torno a las ideas mismas de la soberanía del Estado y la soberanía de la voluntad popular, siendo ambas soberanías de iure y de facto limitadas. Por no hablar de la retórica del control del destino, la supremacía sobre los mares, los imperios donde no se pone el sol, los imperios que son el centro del cielo y de la tierra, la eternidad de las naciones, y demás. $\mathrm{Y}$ ahora, por ejemplo, de lo que se suele llamar el control del cambio disruptivo exponencial del mundo global (que es, por supuesto, mucho más que «el mero mundo»). Una grandilocuencia que tiene, por lo demás, como casi todo, su núcleo razonable; pero que, hasta ahora, ha inducido e induce, a (muy) poco que se enardezcan los ánimos, a diversas formas de delirio.

¿A qué se refiere, normalmente, hoy, esta capacidad estratégica? Obviamente (y dejando aparte los retos geoestratégicos) a la solución de una serie de problemas económicos y sociales mediante las correspondientes políticas públicas. Pero baste recordar lo que hoy parece del dominio público. Hay una crisis económica larga y profunda, con todo lo que, en muchos casos, por lo pronto en Occidente, la acompaña ${ }^{9}$. Una parte importante de la sociedad está en condiciones muy o bastante vulnerables; el horizonte de oportunidades de mejora se achica para una gran parte de las clases medias, trabajadoras y populares; y una desigualdad creciente cuestiona la experiencia de un vivir en común ${ }^{10}$. Al tiempo, la desafección política se puede combinar con un clima de indignación moral vivido en parte de manera genuina, y en parte como una coartada para la expresión del desprecio mutuo. En estas circunstancias, la solución de los problemas socioeconómicos se torna aún más difícil.

\footnotetext{
9 Obviamente me estoy refiriendo a la situación de Occidente; pero conviene no perder de vista tanto el contraste como la analogía entre lo que ocurre en Occidente y lo que sucede en otras partes del mundo; $y$, por poner un ejemplo, conviene atender a las complejas relaciones y tensiones que se dan en la China actual entre el establishment político y económico y las corrientes del neomaoísmo; a título de ilustración puede verse ANDERLINI (2016).

10 Una desigualdad que no es solo social y económica sino también política, de modo que algunos observadores pueden hablar de un lower third, un tercio inferior que habría sido, se supone, cada vez más marginalizado (MERKEL, 2014).
}

Porque falta la comunidad que, como suerte de agente colectivo, se enfrente a ellos.

Es decir, al situar el análisis de la capacidad estratégica del agente en cuestión en un marco, digamos, relacional y reflexivo nos topamos con un vacío ${ }^{11}$. El vacío de una comunidad, por lo pronto, de deliberación y decisión. Se tiene la sensación de que apenas hay un relato o una conversación que suscite el esbozo de un proyecto futuro y la narrativa de una historia suficientemente compartida. Se tiene la impresión de que se ha perdido, o se está perdiendo, el sentimiento de «un nosotros autobiográfico» ${ }^{12}$. El «nosotros» se diluiría entre las manos, y nos quedaríamos con los restos de una comunidad amnésica, que no sabe quién es porque no sabe siquiera quién ha sido. $Y$ sin rumbo. Claro que es extraño que una comunidad así pretenda desempeñar un papel en el horizonte europeo. (¿Cómo lo haría? ¿A golpe de voluntarismo?). Aunque quizá la extrañeza se disimula, y se agrava, con el hecho de que, en este caso, a Europa le ocurre algo semejante. Lo que es, por cierto, una forma más que dudosa de prepararse unos y otros para ese mundo de tensiones geoestratégicas crecientes que casi todos nos anuncian.

Que las elites y las contra-elites tengan astucia tacticista para sobrevivir en esta situación, en el muy corto plazo, no es dudoso. Han demostrado con creces, tanto que pueden hacerlo como que pueden perecer en el empeño; lo que da al espectáculo de su lucha por el poder un toque de suspense interesante. Pero lo que no está claro es que tengan la capacidad estratégica para manejar el proceso en un plazo no tan corto, en el medio, en el largo. Para proporcionar dirección y motivación a las gentes; articular el relato o la conversación; reconstruir la comunidad un día sí y otro también.

\footnotetext{
11 Los agentes, todos, solo existen en una relación de unos con otros, y con la urdimbre de sus actividades y sus interacciones y los productos de las mismas; y esa relación está penetrada, en una medida importante, por grados y modalidades diversas de reflexividad. Ver ARCHER (2013).

12 PÉREZ-DÍAZ (2003a, 418-424; así como 2003b, y 2004), aplicando un esquema conceptual desarrollado en otro ámbito académico, el del «se autobiográfico» (DAMASIO, 2000).
} 


\section{El contexto relacional y reflexivo, y la cuestión de la legitimidad}

Si nos colocamos en la perspectiva del presente continuo en el que estamos ( $\mathrm{y}$ no en la del futuro, tal vez preñado de cambios disruptivos y exponenciales desconcertantes, por llegar) nos encontramos con que las elites y las contra-elites suelen fallar, o están fallando, en tal empeño, lo bastante como para que quede claro que no nos basta con ellas; ni siquiera para lo que se refiere al presente (sin entrar en el futuro). No bastan, ni mucho menos. De aquí que su legitimidad parezca en entredicho. Ahora bien, aquí tal vez nos convenga redefinir el marco interpretativo de esa legitimidad.

En el lenguaje de los expertos, se llama a veces output legitimacy a la legitimidad que resulta de que los líderes políticos sean capaces de resolver los problemas de la sociedad; e input legitimacy a la que se deduce de que la clase política, al resolverlos, tenga muy en cuenta las preocupaciones y peticiones que los ciudadanos ponen en su conocimiento (Scharpf, 1999). Pero el esquema se queda corto a la hora de interpretar el proceso político. Hay algo más, a lo que se ha intentado dar nombre con la expresión, un tanto barroca, de throughput legitimacy (Schmidt, 2013). Se trata de reconocer que el papel de los ciudadanos en el proceso político suele, y debe, desbordar lo que se reduce a una expectativa de soluciones y una comunicación de deseos. Y cuando las elites políticas no ven este «algo más» no hacen sino confesar, en una especie de lapso freudiano, que no acaban de darse cuenta de que no pueden resolver los problemas, ni entender siquiera lo que les comunican los ciudadanos, sin una contribución sustancial de la ciudadanía misma.

Por lo pronto, esto significa que la contribución de los ciudadanos no se limita a los aspectos menores, secundarios, de la llamada democracia participativa. Abarca un amplísimo espectro de actividades cuyos agentes «naturales», en el marco de las sociedades occidentales de estos últimos siglos por lo pronto, son todos y cada uno de los miembros, organizados en uno $u$ otro grado y una $u$ otra forma, de la sociedad civil $^{13}$. Pero incluso por lo que se refiere a las actividades consideradas, en general, como atinentes a los asuntos públicos o del dominio público, los ciudadanos pueden sentirse llamados a actuar o movidos a actuar motu proprio. Y lo han hecho y lo están haciendo de manera creciente. Esto es, en buena parte, lo que ha dado lugar a una ampliación ambigua del lenguaje político, y una suerte de transición de la expresión "gobierno» a la de "gobernanza». Con ello, en el fondo, se trata de reconocer que la ciudadanía puede resolver muchos problemas colectivos por sí misma. Cómo lo haga, será cuestión de debatirlo y de probarlo. Puede hacerlo mediante una combinación que resulte de un continuo experimentar con mercados, redes, autonomías y descentralizaciones administrativas e tutti quanti ${ }^{14}$.

En el fondo de esos experimentos hay unas conversaciones y negociaciones múltiples, diversas, continuas entre ciudadanos y elites y contra-elites, que, a su vez, suponen la apelación a ciertas formas culturales, la referencia a ciertas experiencias, y la búsqueda de cierta forma de comunidad.

Es lógico que la apelación a la cultura sea compleja $y$, de algún modo, ambigua. Pero, dejando aparte esta complejidad y ambigüedad inherentes a lo que suele ser una dilatada trayectoria histórica, situándonos en el presente, por lo pronto, no parece que le convenga a la ciudadanía apelar a demasiados salvadores y exorcistas, de manera imprudente. Aunque tal vez sí pueda y deba manejarse, a la manera de la «política antigua», con algunos rituales de exorcismo, digamos, benévolo, tanto para reducir los excesos del odio

\footnotetext{
${ }^{13}$ Sobre los diversos usos de este concepto de sociedad civil puede verse PÉREZ-DÍAZ (2011 y 2014).

14 La experimentación con diversas formas de gobernanza se extiende a todos los niveles y todos los sectores. Es creciente a nivel global (SALAMON, ed. 2002; KEANE, 2003 y NYE, 2015), y por supuesto europeo (LENDVAI, 2005; SABEL y ZEITLIN, eds. 2012 y TORFING y SORENSEN, 2014). Y afecta al manejo del sistema de bienestar, de la esfera pública, o de la aportación de los expertos, por poner unos ejemplos (ver las contribuciones de JOHANSSON y HVINDEN, NEWMAN, y BANG, en NEWMAN, ed. 2005).
} 
acumulado como para compensar los defectos del escaso gozo que muchos obtienen de estar juntos. En todo caso, en el manejo de estos ritos de duelo y de fiesta, no hace falta recurrir a una nueva encarnación de alianzas del trono y el altar, esta vez bajo la égida de oficiantes secularistas portentosos. Quizá baste, al menos para comenzar, con volver a lo básico, a un respeto por el humus de la tierra que nos haga un poco más humildes, y a las tradiciones de sentido común y de sentido moral que hayan sobrevivido, como lo han hecho, en muchos casos, impregnadas de experiencias religiosas, purificadas, en lo posible, por los (muchos) dramas de rigor ${ }^{15}$. En la esperanza de que, de una u otra manera, se hayan ido formando, por ejemplo, en torno a cultos de dioses lares y penates, o de profetas de la proximidad, las bases de la resistencia de la sociedad frente a la proliferación de juicios no solo parciales, sino también desorbitados (Dunn, 1996) en el debate colectivo. Y si no se han formado aún, seguir intentándolo.

A todo esto ayuda el analizar la experiencia histórica, propia y ajena. Que, estando tan llena de errores, es, a estos efectos, de una riqueza desbordante. De modo que antes de que se destruya la posibilidad de acceder a las fuentes de la memoria colectiva, cuando aún estamos a tiempo de volver a ellas, podamos leer libros de historia, retrotraernos al pasado, descubrir lo que somos a la luz de lo que entre todos ya hemos sido, y quedar, antes de que nos absorba el agujero negro de un futuro vacuo. De aquí la importancia de lo que llamaría las experiencias recalcitrantes del pasado próximo (a las que me referiré en el próximo apartado).

Pero ahora quiero insistir en el tema de la comunidad de referencia; que viene a ser la culminación del argumento sobre la dimensión relacional y reflexiva antes esbozado.

Porque, justamente, de todo lo anterior puede deducirse cuál sea la demanda principal que la ciudadanía

\footnotetext{
15 Relación compleja entre las diversas tradiciones culturales, religiosas incluidas, en la que no puedo entrar aquí (PÉREZ-DÍAZ, 2014).
}

puede plantear en este momento de crisis al sistema político: la de un aumento sustancial de su capacidad estratégica, la de la propia ciudadanía. Porque si la capacidad de las elites y las contra-elites es limitada, y lo es de manera radical, habrá que saber juzgarla y complementarla, y sustituirla por la capacidad y la actuación, también limitadas, de la ciudadanía correspondiente.

Se trata de una demanda que es, paradójicamente, al tiempo, una oferta: el ofrecimiento de un servicio al común que es, en cierta manera, un autoservicio. $Y$ que ofrece una oportunidad para recobrar el sentido de las palabras antiguas, según las cuales, ordenar (de poner orden y de imponer una orden) solo tiene el sentido de que «ordenar es servir» (Dalarun, 2012).

Ahora bien, es obvio que esta demanda debe ser dirigida por la sociedad, por lo pronto, a sí misma, y comenzar con el reconocimiento de que, de entrada, ella misma puede carecer también de esa capacidad. Adquirirla implica una educación, incluida una autoeducación, cívica. No desentenderse de los problemas comunes. Enterarse de los temas, usando con (suficiente) discernimiento los materiales puestos a su disposición por el sistema educativo, la industria de la cultura, la información y el entretenimiento dados, amén de los políticos y las elites y contra-elites de turno, y, en especial, el entorno social (y familiar) en el que cada cual se desenvuelva. Tiene que desarrollar su capacidad de escucha y conversación y convivencia razonables para intervenir en el espacio público. Y es así como puede, y debe, contribuir decisivamente a la recreación continua de la comunidad política.

\section{La recreación continua de la comunidad política}

Al plantear el problema de esta recreación no me refiero a una creación ex nihilo, ni a un texto o un momento fundacional, sino a una reconstrucción y reproducción continuas de la comunidad política. Hablo de una comunidad que perdura en el tiempo, al menos el tiempo suficiente como para colmar, o calmar, la angustia 
existencial, normal, de los seres humanos por permanecer. En este caso, hacerlo como parte de una cadena de generaciones que se prolonga hasta un tiempo supuestamente inmemorial, en el pasado, y promete quedar, indefinidamente, en el futuro. Un relato que intenta reflejar, articular, hacer justicia a la trayectoria de un sujeto relativamente unitario, con un grado suficiente de coherencia, al menos como para que evite un estado de bipolaridad agudo, y sea reconocible en sus ambigüedades, sus dramas y sus mutaciones.

En las condiciones actuales, en general, ni el establishment ni el anti-establishment, ni la clase política establecida ni la ansiosa por establecerse parecen estar en condiciones de ofrecer el relato, la estrategia y la experiencia que permiten crear y recrear esa comunidad. Porque, por definición, dividen la comunidad por partida doble. Primero, en dos bandos, entre «unos y otros», digamos, izquierdas y derechas. Y segundo, entre "ellos y nosotros», entre quienes lideran, las elites mismas, y la ciudadanía o la sociedad civil, quienes, aunque supuestamente nombran a sus dirigentes siendo dueños de su destino durante los 30 segundos en que introducen su papeleta en las urnas, se encuentran luego en la tesitura de secundarles durante cuatro años, o los que correspondan.

Una de las formas que los políticos tienen de establecer esa comunidad doblemente dividida es la de ofrecer, con la ayuda de los expertos en estas materias, un marco interpretativo de la política entendida a la manera de un mercado político, en términos de demandas y ofertas políticas. Según ello, la ciudadanía formularía sus demandas, normalmente muy influidas por los términos mismos en los que las elites definen los problemas y sus soluciones, imaginando que éstas las aplicarán de modo que se satisfagan sus intereses y deseos. Y, llegado el momento, compraría la oferta correspondiente, que vendría a ser como comprar la expectativa de que tales deseos serían satisfechos.

Pero dado el marco interpretativo que las elites construyen y proponen, las demandas y las ofertas vienen sesgadas, porque en su base hay una comunidad impregnada de un conflicto civil permanente. Con la implicación consiguiente de la negación de sí como comunidad. Lo cual introduce una dimensión en cierto modo letal en la vida política, una suerte de proceso de entropía, una propensión a la difusión de un estado emocional de acidia, de sabor de tristeza cívica. Lo que, salvo un notable esfuerzo contrario, tiende a retrotraernos una y otra vez al borde de la escena del capricho goyesco.

\section{Experiencias recalcitrantes y sentido común}

Así pues, dada la limitación de la capacidad estratégica de las elites para resolver la crisis, en este caso, y recrear/reproducir la comunidad misma, la alternativa es... por una parte, soñar bajo alguna de las dos formas habituales. Primera, la del estado de sonambulismo suscitado por los manejos del establishment ${ }^{16}$. Segunda, la de las alucinaciones delirantes propuestas por el anti-establishment. Y por otra parte, despertar y desarrollar la capacidad estratégica de la propia ciudadanía. Cómo hacerlo depende en buena parte de los recursos intelectuales, morales y emocionales, amén de políticos, jurídicos, económicos de una ciudadanía o una sociedad civil que no se deje llevar del «espíritu de servidumbre» (La Boétie, 1976 [1576]). Y ya puestos, que ponga el foco de su atención en la demanda central de aumentar su capacidad estratégica como ciudadanía, como sociedad civil, y de hacer valer sus propuestas, acertando en la «conversión de

\footnotetext{
16 Tan excitantes para el establishment y su entorno y tan lejanos para la ciudadanía. Que puede descubrir, como sin querer, la irrelevancia emocional de esos manejos para ella misma, cuando los Gobiernos y las oposiciones se encuentran en una suerte de limbo, hay «Gobierno en funciones», y las masas descubren que «no pasa nada», y que incluso los remedos de agitación (reforzados por sus ecos mediáticos) sobre qué pensarán o no pensarán las elites en ese estado de suspense carecen de interés, entre otras cosas porque repiten slogans pero apenas piensan. $Y$ solo faltaría la voz de la infancia que nos dijera que el rey iba desnudo; solo que tampoco esta voz sería tan inocente si silenciara el pequeño detalle de que la economía y el sistema legal seguían funcionando. Una «ceremonia de la confusión» que refleja lo que en buena parte ha sucedido en los más de 300 días de gobierno en funciones en la España reciente, y los otros tantos en Bélgica hace no tanto tiempo, por ejemplo.
} 
poder» (Nye, 2015, 87) por la que se transforma aquella capacidad en influencia efectiva.

Y para que no decaiga en la sumisión a las elites y las contra-elites de ocasión, es importante que entienda, insisto, que no se trata de afirmar una mera voluntad de poder. Sino de encarnar una razón práctica que es parte de una cultura vivida razonable y reconciliada, anclada en una (muy larga) tradición de sentido común y de sentido moral. Lo que no debería ser tan difícil de conseguir si se recurre a la experiencia, y, para empezar, al recuerdo, tan próximo, de la «experiencia recalcitrante» ${ }^{17}$ de los totalitarismos, y sus variaciones, de los últimos tiempos. Me refiero a una experiencia rechazable, y rechazada, no como una mera propuesta conceptual, sino como una vivencia insoportable; y no solo por determinadas minorías sino, sobre todo, por la gente del común. Bajo un impulso que aunque quizá no atine con las palabras justas, las reconoce y las solicita. El impulso de la mujer que, en la cola interminable de familiares tratando de enviar víveres a seres queridos, perdidos en el Gulag, se acerca a Anna Ajmátova y le susurra al oído « ¿Y usted puede dar cuenta de todo esto?», y ella le contesta «sí, puedo» ${ }^{18}$.

Queda aún el recuerdo vivo de esta y otras experiencias recalcitrantes en todas partes. De aquí que, en contra de lo que a veces esperan encontrar los estudiosos de la opinión pública por la vía de las encuestas, los resultados de éstas sigan siendo los de una valoración muy alta de la democracia frente a sus alternativas, prácticamente de manera ininterrumpida y estable durante las últimas décadas, con o sin crisis económica por medio (Merkel, 2014). Si el totalitarismo es tabú, tampoco gozan de mucho mejor predicamento términos de referencia como oligarquías o populismos, que, indispensables en el debate académico, sin embargo,

\footnotetext{
17 Puede verse, respecto a la función de la «experiencia recalcitrante» en el desarrollo del razonamiento político moral, PÉREZ-DíAZ (1984, 21 y ss.), partiendo de la teoría pragmatista corporatista de WHITE, M. (1981).

${ }^{18}$ Ver el prólogo (escrito en 1957) de AJMÁTOVA, A. a su libro de poemas Réquiem en AJMÁTOVA y TSVETÁIEVA (2010).
}

en la esfera pública, suelen funcionar como armas arrojadizas.

Pero es de destacar que este apego a la idea de la democracia viene de la mano con una notable practica de la democracia misma, y, en particular, se expresa a través de respuestas bastante más graduadas y coherentes de lo que se suele admitir, a preguntas de carácter institucional o relativas a las preferencias de unos y otros sobre determinadas políticas públicas. A este respecto, la voz de la sociedad civil, en tanto que ciudadanía de a pie objeto de encuestas (una de sus muchas variedades de voz a tener en cuenta) puede ser bastante aleccionadora. Porque puede revelar, como lo ha hecho por ejemplo en una encuesta española reciente (ASP, 2016), una manera de entender la política contemporánea en la que se manifiesta un deseo de referencias estables para la convivencia política, un manejo juicioso de las diversas identidades políticas, y una suerte de prudencia razonable en las políticas económicas y sociales por realizar, llegando aquí bastante lejos, incluso en el detalle, respecto a una serie de reformas, combinadas con continuidades ${ }^{19}$. Políticas decididas a la vista de los resultados de unas y otras, que se trataría de calibrar en cada momento, intentando mejorar la pauta de las que ya se han experimentado a lo largo del tiempo. Todo lo cual supondría un razonamiento complejo y una disposición al compromiso, y una apertura del espacio de reflexividad del conjunto: todo ello bastante lejano del simplismo y la polarización que suelen atribuir a esta opinión pública las elites y contra-elites, del establishment y del anti-establishment.

Cabe imaginar incluso que, por retomar las imágenes del comienzo de este breve ensayo, aquellos ciudadanos de a pie pudieran querer algo parecido a un remake de la escena de convivencia más o menos gozosa del cuadro ya mencionado de Goya, el de la Pradera de San Isidro. En cuanto a los problemas planteados por

\footnotetext{
19 Pueden verse los detalles en ASP (2016); pero, resultados semejantes se encuentran en otros muchos estudios, sobre muy diversos campos de políticas públicas, a título de ejemplo, en el tema educativo en PÉREZ-DÍAZ, RODRÍGUEZ y FERNÁNDEZ (2009).
} 
los sesgos introducidos por los medios, los partidos, las elites de uno u otro signo, cabe imaginar que pueden llevarnos a una senda de caos o, por una ironía de la historia, o astucia de la razón que dijera Hegel, a una senda que se puede intentar recorrer con mejor ánimo y provecho. Pueden ser útiles, o pueden ser un estorbo pero serlo de modo que se les pueda usar a modo de advertencia. En todo caso, siempre puede ocurrir que algunos de ellos, o muchos de ellos, aprendan, o incluso experimenten un proceso de conversión.

Pero quede claro que la esperanza, incluso esta modalidad aroniana de la esperanza, no excluye el apocalipsis. De hecho, los experimentos europeos de estos últimos siglos contienen experiencias de los dos tipos. Experiencias de convivencias razonables, de mundos habitables; y experiencias como las del holocausto, el gulag, dos guerras mundiales, y, ahora, una «nueva normalidad» inquietante y una aparente pérdida de dirección.

Se trata de mantenerse atento al contraste entre ambos tipos de experiencias, sabiendo que no marcan el futuro, sino que dejan el drama abierto. $Y$ lo dejarán siempre abierto.

\section{Referencias bibliográficas}

[1] AJMÁTOVA, A. y TSVETÁlEVA, M. (2010). El canto y la ceniza. Barcelona, Debolsillo.

[2] ANDERLINI, J. (2016). «The Return of Mao», Financial Times Weekend Magazine, 1-2 de octubre, pp.13-19.

[3] ARCHER, M. (2013). «Reflexivity and the Social Order of the New Millennium», en PÉREZ-DÍAZ, V. ed., Europe and the Global Crisis. Madrid, Gota a Gota, pp. 237-271.

[4] ARNOLD, M. (1995). A Selection of his Finest Poems. ALLOTT, M. ed. Oxford, Oxford University Press.

[5] ANALISTAS SOCIO POLÍTICOS (ASP) (2015). Avance de resultados de la encuesta «Retos de la democracia y el espacio público en España, y en Europa, en la crisis actual». Consultado en agosto 2016 en: http://www.funcas.es/publicaciones/ Docs/AvanceDeResultadosDeLaEncuesta.pdf.

[6] DALARUN, J. (2012). Gouverner c'est servir: Essai de démocratie médiévale. París, Alma.

[7] DAMASIO, A. (2000). The Feeling of What Happens: Body, Emotion and the Making of Consciousness. Londres: Vintage.
[8] DAVIDSON, D. (2001). Inquiries into Truth and Interpretation. Oxford: Clarendon Press.

[9] DUNN, J. (1996). «The Contemporary Political Significance of John Locke's Conception of Civil Society», The Jerusalem Philosophical Quarterly, vol. 45, julio, pp. 327-348.

[10] FAWCETT, P. (2014). «Can't Live With Them, Can't Live Without Them: Why Politicians Matter?» Democratic Theory, vol. 1, no 2, pp. 367-375.

[11] GIRARD, R. (2007). Achever Clausewitz: Entretiens avec Benoît Chantre. París: Carnets Nord.

[12] HAGEN, R-M y RAINER, H. (2016). Les Dessous des Chefs-d'oeuvre: Un Regard Neuf sur les Grands Maîtres. Colonia: Taschen.

[13] HALL, P. (2016). «Varieties of Capitalism in Light of the Euro Crisis», presentado en Annual Meeting of the American Political Science Association, Philadelphia.

[14] HALL, P. (En prensa). «Stanley Hoffmann, the Teacher», Commentaire.

[15] KEANE, J. (2003). Global Civil Society? Cambridge: Cambridge University Press.

[16] LA BOÉTIE, É.. de. (1976 [1576]). Le Discours de la Servitude Volontaire. París: Payot.

[17] LENDVAI, N. (2005). «Remaking European Governance: Transition, Accession and Integration», en NEWMAN, J., ed. Remaking Governance: Peoples, Politics and the Public Sphere. Bristol: The Policy Press, pp. 59-80.

[18] MACINTYRE, A. (2006). The Tasks of Philosophy. Selected Studies, Volume 1. Cambridge: Cambridge University Press.

[19] MARSH, D. (2014). «What is the Nature of the Crisis of Democracy and What Can We Do About it?» Democratic Theory, vol. 1, no 2, pp. 37-46.

[20] MERKEL, W. (2014). «ls There a Crisis of Democracy?» Democratic Theory, vol. 1, no 2, pp. 11-25.

[21] NEWMAN, J. ed. (2015). Remaking Governance: Peoples, Politics and the Public Sphere. Bristol: The Policy Press.

[22] NYE JR., J. (2015). Is the American Century over? Cambridge: Policy Press.

[23] OLSEN, J.P. (2013). «The Institutional Basis of Democratic Accountability», West European Politics, vol. 36, n 3 , pp. 447-473.

[24] PÉREZ-DÍAZ, V. (1984). «El proyecto moral de Marx», en ROJO, L. Á. y PÉREZ-DÍAZ, V. eds. Marx, economía y moral. Madrid, Alianza, pp. 95-180.

[25] PÉREZ-DÍAZ, V. (2003a). La lezione spagnola: Società civile, politica e legalità. Milán: II Mulino.

[26] PÉREZ-DÍAZ, V. (2003b). «Spain's End of the Century», ASP Research Papers, vol. 47(b)/2003.

[27] PÉREZ-DíAZ, V. (2004). «Los puntos débiles de la vida pública española», Papeles de Economía Española, $n^{\circ} 100$, pp. 10-30. 
[28] PÉREZ-DIAZ, V. (2008). El malestar de la democracia. Barcelona. Crítica.

[29] PÉREZ-DIAZ, V. (2011). Sociedad civil, un concepto de múltiples niveles. www.sociopedia.isa

[30] PÉREZ-DÍAZ, V. (2013). «Vulnerable Gods and Mutual Learning Between Religion and Secularism», Sociologica, 1/2013, pp. 1-16.

[31] PÉREZ-DÍAZ, V. (2014). «Civil Society: A Multi-layered concept» Current Sociology, vol. 62, n 6, pp. 812-930.

[32] PÉREZ-DÍAZ, V. (2016). «Un triángulo europeo: el momento de la política», en PÉREZ-DÍAZ, V. et al. Un triángulo europeo: elites políticas, bancos centrales y populismos. Madrid, Funcas, pp. 11-34.

[33] PÉREZ-DÍAZ, V.; MEZO, J. y RODRÍGUEZ, J.C. (2012). La crisis y las autonomías: la sociedad española ante la crisis económica y el sistema de las autonomías. Madrid: Funcas.

[34] SABEL, CH. y ZEITLIN, J. (Eds). (2012). Experimentalist Governance in the European Union: Towards a new Architecture. Oxford: Oxford University Press.

[35] SALAMON y LESTER, M., ed. (2002). The Tools of Government: A Guide to the New Governance. Oxford: Oxford University Press.
[36] SCHARPF, F. (1999). Governing in Europe: Effective and Democratic? Oxford: Oxford University Press.

[37] SCHMIDT, V. (2013). «Democracy and Legitimacy in the European Union Revisited: Input, Output and 'Throughput'», Political Studies, n 61 , vol. 1, pp. 2-22.

[38] SCHUDSON, M. (1997). "Why Conversation is Not the Soul of Democracy», Critical Studies in Mass Communication, vol. 14, n 4, pp. 297-309.

[39] STREECK, W. (2014). «How Capitalism Will End», New Left Review, $\mathrm{n}^{\circ} 87$, pp. 35-64.

[40] SUNSTEIN, C. (2008). Why Groups Go to Extremes. Washington: The AEI Press.

[41] THOMPSON, M. (2016). Enough Said: What's Gone Wrong with the Language of Politics? Londres: Bodley Head.

[42] TORFING, J. y SøRENSEN, E. (2014). «The European Debate on Governance Networks: Towards a New and Viable Paradigm?» Policy and Society, vol. 33, $\mathrm{n}^{\circ} 4$, pp. 329-344.

[43] VOEGELIN, E. (1989). Autobiographical Reflections. En SANDOZ, E. (Eds). Baton Rouge y Londres. Louisiana State University Press.

[44] WHITE, M. (1981). What Is and What is To Be Done. Oxford: Oxford University Press. 